NASA Technical Memorandum 106923

AIAA-95-2554

\title{
Cryogenic and Simulated Fuel Jet Breakup in Argon, Helium and Nitrogen Gasflows
}

Robert D. Ingebo

Lewis Research Center

Cleveland, Ohio

Prepared for the

31st Joint Propulsion Conference

cosponsored by AIAA, ASME, SAE, and ASEE

San Diego, California, July 10-12, 1995

National Aeronautics and

Space Administration 


\title{
CRYOGENIC AND SIMULATED FUEL JET BREAKUP IN ARGON, HELIUM AND NITROGEN GASFLOWS
}

\author{
Robert D. Ingebo \\ National Aeronautics and Space Administration \\ Lewis Research Center \\ Cleveland, Ohio 44135
}

\begin{abstract}
$\underline{\text { Abstract }}$
Two-phase flow atomization of liquid nitrogen jets was experimentally investigated. They were co-axially injected into high-velocity gas flows of helium, nitrogen and argon, respectively, and atomized internally inside a two-fluid fuel nozzle. Cryogenic sprays with relatively high specific surface areas were produced, i.e., ratios of surface area to volume were fairly high. This was indicated by values of reciprocal Sauter mean diameters, RSMD's, as measured with a scattered-light scanning instrument developed at NASA Lewis Research Center. Correlating expressions were derived for the three atomizing gases over a gas temperature range of 111 to $422 \mathrm{~K}$. Also, the correlation was extended to include water-jet breakup data that had been previously obtained in simulating fuel jet breakup in sonic velocity gasflow. The final correlating expression included a new dimensionless molecular-scale acceleration group. It was needed to correlate RSMD data, for $\mathrm{LN}_{2}$ and $\mathrm{H}_{2} \mathrm{O}$ sprays, with the fluid properties of the liquid jets and atomizing gases used in this investigation.
\end{abstract}

\section{Nomenclature}

A fuel nozzle orifice area, $\mathrm{cm}^{2}$

$A_{d}$ droplet surface area, $\mathrm{cm}^{2}$

$\mathrm{C}_{\mathrm{d}} \quad$ drag coefficient

$\mathrm{D}_{\mathrm{o}} \quad$ liquid-jet diameter, $\mathrm{cm}$

$\mathrm{D}_{32}^{-1}$ reciprocal Sauter mean diameter, $\mathrm{cm}^{-1}$

$\mathrm{D}_{\mathrm{v} .5} \quad$ volume median diameter, $\mathrm{cm}$

go gravitational acceleration, $980 \mathrm{~cm} / \mathrm{sec}^{2}$

k correlation coefficient for Eq. (1)

$\mathrm{k}_{\mathrm{g}}$ thermal conductivity, g-cal $/ \mathrm{sec} \mathrm{cm}^{2}\left({ }^{\circ} \mathrm{C} / \mathrm{cm}\right)$

m droplet weight, $g$
$\mathrm{Nu} \quad$ Nusselt number, based on $\mathrm{D}_{32}$ or $\mathrm{D}_{\mathrm{v} .5}$

n exponent for Eq. (1)

Re Reynolds number, based on $\mathrm{D}_{32}$ or $\mathrm{D}_{\mathrm{v} .5}$

$T_{0}$ ambient airflow temperature, $293 \mathrm{~K}$

t vaporization time, sec

$\mathrm{V}$ fluid velocity, $\mathrm{cm} / \mathrm{sec}$

$\mathrm{V}_{\mathrm{m}} \quad$ rms gas molecular velocity, $\mathrm{cm} / \mathrm{sec}$

W weight flow of fluid, g/sec

We Weber number, based on $D_{32}$ or $D_{v .5}$

$\mathrm{x}$ axial downstream spray sampling distance, $\mathrm{cm}$

$\mu \quad$ absolute viscosity, $\mathrm{g} / \mathrm{cm} \mathrm{sec}$

$\rho \quad$ fluid density, $\mathrm{g} / \mathrm{cm}^{3}$

$\sigma \quad$ surface tension relative to air, dyne/cm

$\underline{\text { Subscripts }}$

a acoustic

c calculated

d droplet

e experimental

f film

g gas

$1 \quad$ liquid

w water 


\section{Introduction}

Gas turbine and rocket engine performance and emissions can be markedly improved when fuel spray surface area is increased sufficiently to give a corresponding increase in vaporization and burning rates. This was demonstrated in Refs. 1 and 2, where it was found that, at constant inlet airstream momentum, the nitrogen oxides emission index varied inversely with the characteristic fuel-spray drop size. This was attributed to combustion rates being primarily functions of droplet surface area, from which fuel vaporizes and ignites as it reacts with oxygen. Once the initial droplet surface area of the entire spray has been determined, in terms of characteristic dropsize, it is possible to set initial boundary conditions and calculate vaporization and burning rates based on experimentally derived expressions needed to model the over all fuel spray combustion process.

The purpose of the present investigation of liquid nitrogen, $\mathrm{LN}_{2}$, sprays was to obtain characteristic drop size data, in terms of the Sauter mean diameter, $\mathrm{D}_{32}$, and derive a correlating atomization expression that would be valid for fuel, water and cryogenic liquid-jet breakup in high-velocity gas flow. Drop size expressions for liquid sprays, are needed that will cover wide ranges of liquid properties so that they can then be readily used in fuel spray combustion and icing wind-tunnel studies. In the present study, three different atomizing gases were used. Therefore a wide range of gas properties could be included in the derivation of an expression relating Sauter mean diameter to atomizing gas mass flux. Drop size measurements were made close to the fuel nozzle orifice and used to calculate the original unvaporized spray drop size.

A two-fluid fuel nozzle, similar to that used in the space shuttle main engines, was selected for the present study. It had been previously used, as reported in Ref. 3, in studying the atomization of water jets that simulated fuel-jet breakup in high-velocity gasflows. Large numbers of very small droplets, i.e., water sprays having high surface-area to volume ratios, were produced within the two-fluid atomizer. A high ratio of surface-area to volume is desirable since it promotes very rapid rates of vaporization and combustion. When the atomizing gas velocity is relatively high, i.e., at sonic velocity, fuel jet atomization rapidly occures within a two-fluid nozzle and spray formation is relativly complete at the nozzle orifice. Therefore, the initial spray drop size produced by the nozzle will not be appreciably affected when the spray is injected into high temperature and high velocity combustion gases. Once the characteristic drop size produced by this type of nozzle is known, it can be readily used in a combustion environment even though measurements used to determine the spray characteristic dropsize were made in an atmospheric-pressure test section. However, such measurements must be made in the breakup regime of aerodynamic stripping, i.e., liquid jet atomization in highvelocity gas flows.

Atomization studies, as discussed in Refs. 3 and 4, have been made with the scattered-light scanner developed at NASA Lewis Research Center to determine the effect of liquid jet and atomizing gas properties on the drop size of cryogenic and fuel-simulated water sprays. The results of these studies were intended primarily for spray combustion studies and rocket combustor applications. In the case of combustion studies, it is generally preferred to use Sauter mean diameter, $\mathrm{D}_{32}$, to characterize the sprays. However, it should be noted that the reciprocal SMD is a measure of the specific surface-area of a fuel spray and it can be used to simulate the diameter of a single droplet that has the same area to volume ratio as that of all of the drops in the spray. In this RSMD form, $\mathrm{D}_{32}^{-1}$ is useful in calculating fuel spray vaporization and combustion rates, in terms of droplet Reynolds and Nusselt numbers for momentum and heat-transfer from gasflows to sprays.

The primary purpose of the present atomization study, was to obtain a single correlating expression for $\mathrm{D}_{32}^{-1}$ that would be valid for many different liquid jets and atomizing gases and thereby cover a wide variety of fluid properties. To do this, it would be necessary to correlate drop size data obtained from $\mathrm{LN}_{2}$ jet breakup studies with data previously obtained for water spray studies. The resulting expression would then be applicable not only to fuel and cryogenic sprays obtained with a two-fluid fuel nozzle but also useful in wind-tunnel studies to determine airfoil performance under simulated icing weather conditions.

In the previous study of $\mathrm{LN}_{2}$ jet atomization described in Ref. 4, drop size measurements were made in the presence of relatively high thermal gradients. When the atomizing gas temperature was $295 \mathrm{~K}$, the $\mathrm{LN}_{2}$ droplet temperatures were near the boiling point of $77 \mathrm{~K}$. Thus the heat transfer driving potential across the gas film was $218 \mathrm{~K}$. This is considerably higher than that encountered in the water spray study that is described in Ref. 3, in which the temperature difference was only $13 \mathrm{~K}$, at $\mathrm{T}_{\mathrm{g}}=$ $295 \mathrm{~K}$. Thus it was found that droplet vaporization had very little effect on water spray measurements, when drop size data were taken close to the atomizer orifice. However in the present study of a cryogenic liquid, it was found that $\mathrm{LN}_{2}$ jets very quickly disintegrated into large numbers of very small droplets. Some of the smallest drops were completely vaporized before passing through the laser beam of the drop sizing insturment. As a result, it was only possible to make measurements of partially vaporized $\mathrm{LN}_{2}$ sprays.

Heat and momentum transfer relationships, which were obtained from the droplet studies described in Ref. 5, were used to determine the effect of droplet vaporization on $\mathrm{D}_{32}$. This was made possible by using expressions for heat- 
transfer and drag coefficients, given in Ref. 5, to calculate unvaporized characteristic drop size, $\mathrm{D}_{32 c}$, for the $\mathrm{LN}_{2}$ sprays. Thus Sauter mean diameter data obtained in the present cryogenic spray study could be compared with data obtained in Ref. 2 for water sprays. This comparison is possible since the effect of droplet vaporization on the drop size of water sprays was negligible for measurements made close to the nozzle orifice.

Numerous investigators, as reported in Refs. 6 to 10 , have studied the effect of atomizing-gas velocity, $\mathrm{V}_{\mathrm{g}}$, on liquid jet atomization. According to predictions of atomization theory, $\mathrm{D}_{32}$ is proportional to $\mathrm{V}_{\mathrm{g}}^{\mathrm{n}}$, where $\mathrm{n}=-1.33$. Some of the investigators have reported drop size measurements that gave values of $n$ as low as -1.00 . On the other hand, some found that their drop size measurements gave $\mathrm{V}_{\mathrm{g}}$ exponents that agreed with atomization theory, as shown in Table I. Such a discrepancy in results could be attributed to the effect of droplet vaporization on drop size measurements, when they were made at distances that were relatively far downstream of the atomizer orifice. This was found to be the case in Ref. 11, when water spray sampling distances were increased from 2.2 to $6.7 \mathrm{~cm}$. This caused the exponent $\mathrm{n}$, for $\mathrm{V}_{\mathrm{g}}$, to decrease from -1.33 to -1.00 , as a result of the effect of drop vaporization on drop size measurements.

The scattered-light scanner used in this study to measure $\mathrm{D}_{32}$ was developed by Buchele, Ref. 12. The $\mathrm{LN}_{2}$ sprays were sampled with the upstream edge of the laser beam located at a distance of $2 \mathrm{~mm}$ downstream of the fuel nozzle orifice. This tended to minimize but not eliminate the effect of droplet vaporization, on the change in surface area, that produced partially vaporized sprays. To evaluate the performance of the two-fluid fuel nozzle, three different atomizing gases, i.e., $\mathrm{He}, \mathrm{N}_{2}$ and $\mathrm{Ar}$, were studied over a gas temperature range of 111 to $422 \mathrm{~K}$. Results of this investigation were then compared with those obtained from previous water spray studies.

\section{Apparatus and Procedure}

A diagram of the two-fluid fuel nozzle used in this study of multiphase flow atomization of cryogenic liquid jets is shown in Fig. 1. It was mounted on the center line of a 24-cm diameter test section so that $\mathrm{LN}_{2}$ sprays could be injected downstream into low-velocity airflow, as shown in Fig. 2. Drop size measurements of the sprays were made with a laser scattered-light scanner. The upstream edge of the laser beam was located at a distance of $2 \mathrm{~mm}$ downstream of the fuel nozzle orifice, as shown in Fig. 3. The atomizer was operated at $\mathrm{LN}_{2}$ and atomizing-gas pressures ranging from 0.2 to $1.0 \mathrm{MPa}$.

At a temperature of $77 \mathrm{~K}, \mathrm{LN}_{2}$ was injected into the airstream flowing outside of the fuel nozzle by gradually opening the control valve until a desired flowrate of
$51 \mathrm{~g} / \mathrm{sec}$ was obtained, as indicated by a turbine flowmeter. The atomizing gas, i.e., $\mathrm{He}, \mathrm{N}_{2}$ or $\mathrm{Ar}$ was then turned on and gas weight flowrate was measured with a $0.51-\mathrm{cm}$ diameter sharp-edge orifice. After setting gas and $\mathrm{LN}_{2}$ flowrates, the characteristic drop sizes, $\mathrm{D}_{32}$ and $\mathrm{D}_{\mathrm{v} .5}$, were measured with the scattered-light scanner.

Fig. 3 shows the scattered-light scanner optical system. It consists primarily of a laser beam expander with a spatial filter, rotating scanning slit and a detector. Scatteredlight measurements were made as described in Ref. 12 This was accomplished by repeatedly sweeping a variable length slit through the collecting lens focal plane. Scattered-light energy data was obtained as a function of scattering angle relative to the laser beam axis. A similar method of measurement of particle size is described in Ref. 13.

According to Ref. 12, scattered-light energy measurements can be normalized by maximum energy and plotted against scattering angle to obtain characteristic drop sizes of sprays. This method was used in the present study to determine both the Sauter mean diameter, $\mathrm{D}_{32}$, and volume median diameter, $\mathrm{D}_{\mathrm{v} .5}$. Not only can this method be used to determine characteristic drop size but it can also be used to determine drop size dispersion, that is independent of the particle size distribution function, as discussed in Ref. 12. Also, it should be noted that the scan is repeated 60 times/sec. This averages out any temporal variations in the energy curve.

The effect of spray pattern variations on drop size data was minimized by sampling an entire cloud of droplets with the laser beam. The instrument was calibrated with five sets of monosized polystyrene spheres with diameters of $8,12,25,50$, and $100 \mathrm{~m}$, respectively. The $\mathrm{LN}_{2}$ sprays were sampled very close to the atomizer orifice and therefore contained relative high number-density clouds of very small droplets. As a result, light-scattering measurements required corrections for multiple scattering, as derscibed in Ref. 14. Also, drop size measurements were corrected to include Mie scattering theory, when very small droplets having diameters of $10 \mathrm{~mm}$ or less were measured.

Repeatability tests gave agreement of experimental measurements within \pm 5 percent. The effect of severe density gradients on background readings was eliminated by taking readings with one of the high-temperature atomizing gases flowing through the fuel nozzle. This made it possible to correct the light-scattering curves so that accurate drop size measurements could be made.

\section{Experimental Results and Discussion}

The reciprocal Sauter mean diameter, RSMD, was measured by sampling the entire liquid nitrogen, $\mathrm{LN}_{2}$, spray cross section, with the laser beam center line 
located $1.2 \mathrm{~cm}$ downstream of the fuel nozzle orifice, as shown in Fig. 1. Most of the $\mathrm{LN}_{2}$ droplets were partially vaporized as they traveled a distance of $1.9 \mathrm{~cm}$ through the scattered-light scanner laser beam. Some of the very small droplets were completely vaporized before they could exit the laser beam. As a result, only measurements of $D_{32 \mathrm{e}}$ were obtained for partially vaporized sprays and it was necessary to calculate the change in drop size that occured, in order to determine the initial unvaporized spray drop size, $D_{32 c}$, formed at the fuel-nozzle orifice. Such data is needed to correlate initial $L_{2}$ spray values of $D_{32 c}$ with $\mathrm{D}_{32}$ data previously obtained for appreciably unvaporized water sprays, as produced with two-fluid fuel nozzles and reported in Ref. 3.

\section{Correlation of $\mathrm{D}_{32 \mathrm{e}}$ With Atomizing-Gas Flowrate}

Experimental values of $D_{32}$ were obtained, for partially vaporized sprays, and plotted against atomizinggas flowrate, $\mathrm{W}_{\mathrm{g}}$, as shown in Fig. $4 . \mathrm{LN}_{2}$ jet breakup occurred primarily in the aerodynamic stripping regime of liquid jet breakup, in high-velocity gas flow. Secondary breakup of droplets was not observed since the lowgas velocity regime of capillary wave breakup of liquid jets was not investigated. Thus, the following expression was derived from the data plot shown in Fig. 4:

$$
\mathrm{D}_{32 \mathrm{e}}^{-1}=\mathrm{k}_{\mathrm{e}} \mathrm{W}_{\mathrm{g}}^{\mathrm{n}}
$$

Values of exponent $\mathrm{n}$ and correlating coefficient $\mathrm{k}_{\mathrm{e}}$ are given in Table II for the three atomizing gases helium, argon and nitrogen, respectively. For example, the following expression was obtained for nitrogen gasflow:

$$
\mathrm{D}_{32 \mathrm{e}}^{-1}=385 \mathrm{~W}_{\mathrm{g}}^{1.11}
$$

where values of $\mathrm{D}_{32 \mathrm{e}}$ and $\mathrm{W}_{\mathrm{g}}$ are expressed as $\mathrm{cm}$ and $\mathrm{g} / \mathrm{sec}$, respecatively.

The value of $n=1.11$ does not agree with that of 1.33 predicted by atomization theory, for liquid-jet breakup in high-velocity gasflow. This discrepancy is attributed to the loss of very small $\mathrm{LN}_{2}$ droplets that were completely vaporized before drop size measurements could be completed with the scattered-light scanner.

\section{Simultaneous Vaporization and Acceleration of $\mathrm{D}_{32}$}

The $\mathrm{LN}_{2}$ spray characteristic drop size $\mathrm{D}_{32}$ simultaneously accelerated and vaporized as it traveled through the laser beam, i.e., a distance of $x=2.2 \mathrm{~cm}$. The change in drop size, $\mathrm{dD}_{32}$ over distance $\mathrm{dx}$ was calculated from the following heat-balance expression:

$$
\mathrm{dD}_{32}^{2} / \mathrm{dt}=4 \mathrm{k}_{\mathrm{g}} \Delta \mathrm{T} \mathrm{Nu} / \rho_{1} \mathrm{H}_{\mathrm{t}}
$$

and the momentum balance expression:

$$
m_{d} a=\rho_{g} A_{d}\left(v_{g}-v_{d}\right)^{2} C_{d} / 2
$$

which gives the change in droplet velocity, $\mathrm{V}_{\mathrm{d}}$, and residence time $t$ with distance, as shown in Figs. 5 and 6.

In Eq. (3), $\mathrm{k}_{\mathrm{g}}$ and $\mathrm{r}_{\mathrm{l}}$ are gas thermal conductivity and liquid density, respectively, and $\mathrm{H}_{\mathrm{t}}=\mathrm{H}_{\mathrm{v}}+\mathrm{C}_{\mathrm{p}} \Delta \mathrm{T} . \mathrm{H}_{\mathrm{v}}$ is the latent heat of $\mathrm{LN}_{2}, \mathrm{c}_{\mathrm{p}}$ is the specific heat of nitrogen vapor and and $\Delta \mathrm{T}=\mathrm{T}_{\mathrm{g}}-\mathrm{T}_{1}$. Nusselt numbers for Eq. (3) were calculated from the following expression:

$$
\mathrm{Nu}=2+0.303\left(\rho_{\mathrm{g}} \mathrm{D}_{32} \Delta \mathrm{V} / \mu_{\mathrm{g}}\right)^{0.6}
$$

which was derived in Ref. 5 from drop size data obtained with a high-speed droplet tracking camera. Vaporization rates of Jet-A fuel, n-octane, benzene, acetone, water and several other liquids were obtained in that study. Calculated values of the Reynolds number are also plotted in Fig. 6. Atomizing-gas viscosity and thermal conductivity are evaluated at the average gas-film temperature, i.e., $T_{\mathrm{f}}=\left(\mathrm{T}_{\mathrm{g}}-\mathrm{T}_{1}\right) / 2$. Droplet surface temperature was approximately $77 \mathrm{~K}$, i.e., close to the boiling point of $\mathrm{LN}_{2}$ as the droplets were accelerating and vaporizing. The latent heat of vaporization of $\mathrm{LN}_{2}$ was evaluated at $77 \mathrm{~K}$ and the specific heat of nitrogen vapor was evaluated at the average gas-film temperature.

The rate at which atomizing gases $\mathrm{He}, \mathrm{Ar}$ and $\mathrm{N}_{2}$ decelerated in a surrounding low-velocity airflow was determined as follows. At the fuel nozzle orifice, $x=0$, gas velocity was equal to acoustic velocity, $V_{c}$. Subsequent values of gas velocity, $\mathrm{V}_{\mathrm{g}}$, were calculated from data given in Ref. 15 and plotted over a distance of $3 \mathrm{~cm}$ downstream of the fuel-nozzle orifice, as shown in Fig. 5. Also, it should be noted that the drag coefficient for $\mathrm{D}_{32}$ was calculated from the following expression: $C_{d}=27 \mathrm{Re}^{0.84}$, which was also derived in Ref. 5 .

Vaporization time, $t$, was calculated from the expression $\mathrm{dt}=\mathrm{dx} / \mathrm{V}_{\mathrm{d}}$ and plotted against downstream distance $x$ as shown in Fig. 6. Reynolds mumbers based on characteristic drop diameter, $\mathrm{D}_{32}$, are also plotted against $\mathrm{x}$ and decreased from 380 to 155 as dropleat relative velocity also decreased over a distance of $2.2 \mathrm{~cm}$.

\section{Calculated values of $\mathrm{D}_{32 \mathrm{c}}$}

The initial unvaporized value of $D_{32 c}$ was obtained from experimental measurements of $\mathrm{D}_{32 \mathrm{e}}$, which were corrected for changes in $\mathrm{D}_{32}$, as calculated from Eq. (3). Calculated values of $\mathrm{D}_{32 \mathrm{c}}$ were correlated with atomizing-gas flowrate, as shown in Fig. 7 and the following expression was obtained:

$$
\mathrm{D}_{32 \mathrm{c}}^{-1}=368 \mathrm{~W}_{\mathrm{G}}^{1.33}
$$


when nitrogen was used as the atomizing gas, at a temperature of $295 \mathrm{~K}$. Comparing Eq. (6) with Eq. (2), which was also derived for nitrogen gasflow, shows that the correlating coefficient, $\mathrm{k}$, is nearly the same in both equations. However, the value of exponent $\mathrm{n}$ for the partially vaporized sprays is considerably less, i.e., 1.11 as compared with 1.33 given in Eq. (6). This decrease in exponent, e, indicates a marked effect of droplet vaporization on drop size measurements. Also, it should be noted that Eq. (6) agrees well with graphically determined values of exponent, $\mathrm{n}$, and with atomization theory, Ref. 16 , which predicts that $\mathrm{n}=1.33$ for liquid jet breakup in highvelocity gasflow. This agreement of Eq. (6) with theory indicates the initial characteristic spray drop size, $D_{32 c}$, can be readily computed by using the heat-transfer and drag coefficient expressions reported in Ref. 5. Although some very small droplets are completely vaporized during spray drop size measurements, the characteristic dropsize $\mathrm{D}_{32}$ does travel the entire length of the $1.9 \mathrm{~cm}$ laser beam.

\section{Correlation of $\mathrm{D}_{32}$ with Fluid Properties}

In a previous atomization study reported in Ref. 4 , it was found that the volume median diameter of liquid nitrogen sprays, $D_{v .5}$, could be correlated with the Weber and Reynolds numbers raised to the 0.44 power. However, it was found that the product of Weber and Reynolds number, WeRe, did not adequately show the effect of gas mass flux on spray drop size. Therefore it was necessary to multiply WeRe by the fluid density ratio, which also had an exponent of 0.44 . To obtain a similar correlating expression for the Sauter mean diameter, $D_{32 c}$ was normalized with respect to injector tube inside-diameter, $\mathrm{D}_{\mathrm{o}}$, and plotted against the product of WeRe and fluid density ratio as shown in Fig. 8. $\mathrm{D}_{\mathrm{v} .5}$ data obtained in the present study are also plotted in Fig. 8. The following correlating expression was obtained:

$$
\mathrm{D}_{\mathrm{o}} / \mathrm{D}_{32}=\mathrm{k}\left(\mathrm{WeRe} \rho_{\mathrm{g}} / \rho_{1}\right)^{0.44}
$$

which is similar to that given in Ref. 4 , for the voume median diameter, $\mathrm{D}_{\mathrm{v} .5}$. However the value of $\mathrm{k}$ is different. Also, Eq. (7) may be rewritten in terms of gas mass flux as follows:

$$
\mathrm{D}_{\mathrm{o}} / \mathrm{D}_{32}=\mathrm{k}\left(\mathrm{D}_{\mathrm{o}}^{2} / \rho_{1} \mu_{1} \delta\right)^{0.44}\left(\mathrm{w}_{\mathrm{g}} / \mathrm{A}_{\mathrm{o}}\right)^{1.33}
$$

The first bracketed group primarily demonstrates the effect of liquid-jet properties on Sauter mean diameter. The final group is simply gas mass flux.

From the plots shown in Fig. 8, values of $\mathrm{k}$ based on $\mathrm{D}_{\mathrm{v} .5}$ and $\mathrm{D}_{32}$ were calculated and recorded in Table III, for the three atomizing gases. From these values of $\mathrm{k}$, it is evident that the relationship between Sauter mean diameter, $D_{32}$, and $D_{v .5}$, the volume median diameter, may be expressed as follows:

$$
\mathrm{D}_{32}=1.41 \mathrm{D}_{\mathrm{v} .5}
$$

as based on measurements made with the scattered-light scanner. The constant 1.41, in Eq. (9), is the same as that obtained in calibration tests made with polystyrene spheres.

In order to extend the usefulness of Eqs. (7) and (8), the effects of gas properties on cryogenic spray formation were investigated. Three different atomizing gases were tested and it was found that the variables given in Eq. (7) would not give a single correlating expression for all of the drop size data. Therefore the new dimensionless group that was previously derived in Ref. 4, is plotted against the proportionality constant $\mathrm{k}_{\mathrm{c}}$, of Eq. (7), as shown in Fig. 9. This Figure indicates $k_{c}$ is proportional to the new group raised to the 0.75 power. Thus, with this group it is possible to extend Eq. (6), to cover a wide range of atomizing gas properties. However, to obtain a single correlating expression for atomizing gas temperatures of 111 , 295 and $422 \mathrm{~K}$, it was necessary to multiply the group by atomizing gas temperature normalized with respect to ambient gas temperature, $293 \mathrm{~K}$. As a result, $\mathrm{D}_{\mathrm{o}} / \mathrm{D}_{32 \mathrm{c}}$ was plotted against the dimensionless group in Eq. (7), which was multiplied by the product of the new group and the temperature ratio, as shown in Fig. 10. From this plot, the following expression was obtained for liquid nitrogen sprays:

$$
\begin{aligned}
\mathrm{D}_{\mathrm{o}} / \mathrm{D}_{32 \mathrm{c}}=\mathrm{k}(\text { WeRe } & \left.\rho_{\mathrm{g}} / \rho_{1}\right)^{0.44} \\
& \times\left[\left(\rho_{1} \mathrm{~V}_{\mathrm{m}}^{3} / \mathrm{g}_{\mathrm{o}} \mu_{\mathrm{g}}\right)\left(\mathrm{T}_{\mathrm{g}} / \mathrm{T}_{\mathrm{o}}\right)\right]^{0.75}
\end{aligned}
$$

where $\mathrm{V}_{\mathrm{m}}=(3 \mathrm{RT} / \mathrm{M})^{0.5}$, i.e., the rms gas molecular velocity. As expected, this expression is very similar to the one obtained in Ref. 3 for water sprays. However, values of the correlating constants, that were obtained in evaluating $\mathrm{D}_{32}$ for $\mathrm{LN}_{2}$ and water sprays, are quite different. This was expected since there is considerable difference in their physical properties.

\section{Correlation of $\mathrm{LN}_{2}$ and $\mathrm{H}_{2} \mathrm{O}$ Spray Data}

In a previous investigation using the scattered-light scanner, as discussed in Ref. 3, water sprays were used to simulate fuel sprays and the following expression was derived for liquid jet breakup in $\mathrm{He}, \mathrm{N}_{2}$ and Ar gasflows: 


$$
\mathrm{D}_{\mathrm{o}} / \mathrm{D}_{32}=\mathrm{k}_{\mathrm{w}}\left(\mathrm{WeRe} \rho_{\mathrm{g}} / \rho_{1}\right)^{0.44}\left(\rho_{1} \mathrm{v}_{\mathrm{m}}^{3} / \mathrm{g}_{\mathrm{o}} \mu_{\mathrm{g}}\right)^{0.75}
$$

This expression is quite similar to Eq. (10). However, the temperature ratio, $\mathrm{T}_{\mathrm{g}} / \mathrm{T}_{\mathrm{o}}$, is present in Eq. (10) but not in Eq. (11). In deriving Eq. (11), in Ref. 3, the atomizinggas temperature, $T_{g}$, was $295 \mathrm{~K}$ and $T_{0}=293 \mathrm{~K}$. Therefore the temperature ratio, $\mathrm{T}_{g} / \mathrm{T}_{\mathrm{o}}$, was essentially unity. Thus Eq. (11) for water sprays agrees very well with Eq. (10), that was derived in this study of $\mathrm{LN}_{2}$ jets. The values of $\mathrm{k}$ are $8.15 \times 10^{-11}$ and $4.33 \times 10^{-11}$, for $\mathrm{LN}_{2}$ and $\mathrm{H}_{2} \mathrm{O}$ sprays, respectively.

In comparing the variables that control $\mathrm{LN}_{2}$ and $\mathrm{H}_{2} \mathrm{O}$ jet breakup, it is obvious that considerable differences exist in the properties of the two liquids. Therefore to determine a single value for coefficient $\mathrm{k}$ that would be valid for wide varieties of liquids, i.e., cryogenics, fuel and water, a log-log plot of $\mathrm{k}$ against droplet surface temperature, $T_{1}$, normalized with respect to ambient air temperature, $T_{0}$, was made and it was found that, $D_{0} / D_{32 c}$ $\sim\left(\mathrm{T}_{\mathrm{o}} / \mathrm{T}_{1}\right)^{0.44}$. As a result, the following correlating expression for $\mathrm{LN}_{2}$ and water sprays was obtained from the plots shown in Figs. 11(a) and (b):

$$
\begin{aligned}
\frac{D_{0}}{D_{32}}=4.32 \times 10^{-11}\left[\frac{\rho_{g}}{\rho_{1}}(W e R e) \frac{T_{o}}{T_{1}}\right]^{0.44} & \\
\times & {\left[\frac{\rho_{1}}{\rho_{g}}\left(\frac{\rho_{g}}{\mu_{g}} \frac{V_{m}^{3}}{g_{0}}\right) \frac{T_{g}}{T_{o}}\right]^{0.75} }
\end{aligned}
$$

for multiphase flow atomization, of liquid jets in two fluid fuel nozzles, at high-velocity gasflows. This equation can be rewritten as follows:

$$
D_{32}^{-1}=\frac{C_{32}}{D_{o}}\left[\frac{D_{o}^{2}}{\rho_{1} \mu_{g} \delta}\left(W_{g} / A_{o}\right)^{3} \frac{T_{o}}{T_{1}}\right]^{0.44}\left[\frac{\rho_{1} V_{m}^{3}}{g_{0} \mu_{g}} \frac{T_{g}}{T_{o}}\right]^{0.75}
$$

where $\mathrm{C}_{32}=4.32 \times 10^{-11}$.

By writing the equation in this form, the effect of liquid temperature on $\mathrm{D}_{32}$, as given by the first bracketed term, is clarified. It shows each variable and the power to which it is raised. Thus, Eq. (12b) clearly gives the effect of gas and liquid properties, and especially gas mass flux, on reciprocal Sauter mean diameter, RSMD. Also, by substituting $C_{v .5}$ for $C_{32}$ in Eq. (12b), the value of reciprocal volume median diameter, $D_{v .5}$ is obtained. Since $D_{32}=$ $1.41 \mathrm{D}_{\mathrm{v} .5}$, the value of $\mathrm{C}_{\mathrm{v} .5}$ is $3.0 \times 10^{-11}$. However, Eq. (12b) appears to be the most practical form of the relationship, since it characterizes the spray in terms of
$\mathrm{D}_{32}$, which is a measure of droplet surface area per unit volume of liquid, i.e., $\mathrm{D}_{32}^{-1}=\sum_{\mathrm{i}} \mathrm{nD}_{\mathrm{i}}^{2} / \sum_{\mathrm{i}} \mathrm{nD}_{\mathrm{i}}^{3}$.

\section{Concluding Remarks}

The computational method used in this study is primarily based on numerical integration of momentum and heat transfer expressions previously derived in fuel droplet investigations, at NASA Lewis Research Center. With this method, it was possible to determine the effect of droplet vaporization on cryogenic sprays. With this knowledge and by using experimental data obtained for partially vaporized $\mathrm{LN}_{2}$ sprays, the original negligibly vaporized spray drop size produced at the orifice of the two-fluid fuel nozzle was calculated. As a result, values of reciprocal Sauter mean diameter, RSMD, could then be correlated with negligibly vaporized water spray drop size data to yield an all encompassing expression that covered a wide range of fluid properties, i.e., $\mathrm{H}_{2} \mathrm{O}$ and $\mathrm{LN}_{2}$ jet properties as well as those of $\mathrm{He}, \mathrm{GN}_{2}$, and $\mathrm{Ar}$ atomizing gases.

The effect of atomizing-gas mass flux on RSMD, as shown in the final correlating expression obtained in this study, agreed well with atomization theory for liquid-jet atomization in the regime of aerodynamic stripping, i.e., high-velocity gasflow. This expression, Eq. (13), in it's present form can be readily applied to analytical modeling of vaporization and combustion of fuel sprays, as based on the initial spray drop size.

\section{References}

1. Mularz, E.J., Wear, J.D. and Verbulecz, P.W., "Pollution Emissions from Single Swirl-Can Combustor Modules at Parametric Test Conditions," NASA TM X-3167, 1975.

2. Ingebo, R.D., "Atomizing Characteristics of SwirlCan Combustor Modules With Swirl-Blast Fuel Injectors," NASA TM-79297, 1980.

3. Ingebo, R.D., "Gas Property Effects on Dropsize of Simulated Fuel Sprays," Journal of Propulsion and Power, Vol. 7, Number 4, July-August 1991, pp. 467-472.

4. Ingebo, R.D., "Cryogenic Spray Vaporization in High Velocity Helium, Argon and Nitrogen Gasflows," NASA TM-106363, 1994, AIAA-94-0687.

5. Ingebo, R.D., "Atomization, Acceleration and Vaporization of Liquid Fuels,"Sixth Symposium (International) on Combustion, Reinhold Publishing Corporation, New York, 1957, pp. 684-687.

6. Kim, K.Y. and Marshall, W.R., Jr., "Drop Distributions for Pneumatic Atomizers," AIChE Journal, Vol. 17, No. 3, May 1971, pp. 575-584. 
7. Lorenzetto, G. E., and Lefebvre, A. H., "Measurements of Drop Size on a Plain-Jet Airblast Atomizer," AIAA Journal, Vol. 15, No. 7, July 1977, pp. 1006-1010.

8. Nukiyama, S. and Tanasawa, Y., "Experiments on the Atomization of Liquids by Means of a Air Stream," Parts III-IV," Transactions of the Society of Mechanical Engineers, Japan, Vol. 5, No. 18, Feb. 1939, pp. 6375.

9. Weiss, M.A., and Worsham, C.H., "Atomization in High Velocity Airstreams," American Rocket Society Journal, Vol. 29, No. 4, Apr. 1959, pp. 252259.

10. Wolf, H.E., and Andersen, W.H., "Aerodynamic Break-up of Liquid Drops," Proceedings of the 5th International Shock Tube Symposium, edited by Z. I. Slawasky, J.F. Moulton, Jr., and W.S. Filler, Naval Ordnance Lab., White Oak, MD, 1966, pp. 1145-1169. (Avail. NTIS, AD-6380211.)

11. Ingebo, R.D., "Experimental and Theoretical Effects of Nitrogen Gas Flowrates on Liquid Jet Atomization," Journal of Propulsion and Power, Vol. 4, No. 6, Nov.-Dec. 1988, pp. 406-411.

12. Buchele, D.R., "Particle Sizing by Weighted Measurements of Scattered Light," NASA TM-100968, 1988.
13. Swithenbank, J., Beer, J.M., Taylor, D.S., Abbot, D., and McCreath, G.C., "A Laser Diagnostic Technique for the Measurement of Droplet and Particle Size Distribution," Experimental Diagnostics in Gas Phase Combustion systems, edited by B.T. Zinn and C.T, Bowman, Progress in Astronautics and Aeronautics, Vol. 53, AIAA, New York, 1977, pp. 421-447.

14. Felton, P.G., Hamidi, A.A., and Aigal, A.K., "Measurement of Drop-Size Distribution in Dense Sprays by Laser diffraction," from No. 12 ICLASS-86; Proceedings of the third International Conference on Liquid atomization and Spray Systems, Vol. 2, edited by P. Eisenklam and A. Yule, Institute of energy, London, UK, 1985, pp. IVA/4/1-11.

15. Bulzan, D.L., Levy, Y., Aggarwal, S,K., and Chitre, S., "Measurements and Predictions of a Liquid Spray From an Air-Assist Nozzle," Atomization and Sprays, Vol. 2, 1992, pp. 445-462.

16. Adelberg, M., "Mean Drop Size Resulting From The Injection of a Liquid Jet Into a High Speed Gas Stream," AIAA Journal, Vol. 6, No. 6, June 1986, pp. 1143-1147.
TABLE I.-GAS VELOCITY EXPONENT, n, FOR LIQUID-JET BREAKUP IN HIGH VELOCITY GASFLOW

\begin{tabular}{|c|c|}
\hline Source & Exponent \\
\hline Adelbert, Theory ${ }^{16}$ & 1.33 \\
\hline Present study, $(x=2.2 \mathrm{~cm})$ & 1.33 \\
\hline $\mathrm{Kim}$ and Marshall ${ }^{6}$ & 1.14 \\
\hline Lorenzetto and Lefevbre ${ }^{7}$ & 1.00 \\
\hline $\begin{array}{l}\text { Nukiyama and Tanasawa, }{ }^{8} \\
\quad(x=5 \text { to } 25 \mathrm{~cm})\end{array}$ & 1.00 \\
\hline Weiss and Worsham ${ }^{9}$ & 1.33 \\
\hline Wolf and Anderson ${ }^{10}$ & 1.33 \\
\hline
\end{tabular}

TABLE II.-EXPERIMENTAL $\mathrm{k}_{\mathrm{c}}$ AND $\mathrm{n}$ VALUES FOR EQUATION (1)

\begin{tabular}{|l|r|r|r|r|r|r|}
\hline Gas & \multicolumn{3}{|c|}{$\mathrm{k}_{\mathrm{e}}$} & \multicolumn{3}{c|}{$\mathrm{n}$} \\
\hline $\mathrm{T}_{g}, \mathrm{~K}$ & 111 & 295 & 422 & 111 & 295 & 422 \\
$\mathrm{He}$ & 805 & 1500 & 1820 & 1.20 & 1.19 & 1.10 \\
$\mathrm{GN}_{2}$ & 123 & 385 & 546 & 1.22 & 1.11 & 1.08 \\
$\mathrm{Ar}$ & 65 & 311 & 420 & 1.22 & 1.08 & 1.00 \\
\hline
\end{tabular}

TABLE III--
CALCULATED k
VALUES FOR
EQUATIONS (7)
\begin{tabular}{|l|c|c|}
\hline \multicolumn{3}{|c|}{ AND (8) } \\
\hline \multirow{2}{*}{ Gas } & $\begin{array}{c}\text { Characteristic } \\
\text { drop size }\end{array}$ \\
\cline { 2 - 3 } & $\mathrm{D}_{32 \mathrm{c}}$ & $\mathrm{D}_{\mathrm{v} .5}$ \\
\hline $\mathrm{He}$ & 90.0 & 63.6 \\
$\mathrm{GN}$ & 13.0 & 9.4 \\
$\mathrm{Ar}_{2}$ & 7.8 & 5.7 \\
\hline
\end{tabular}




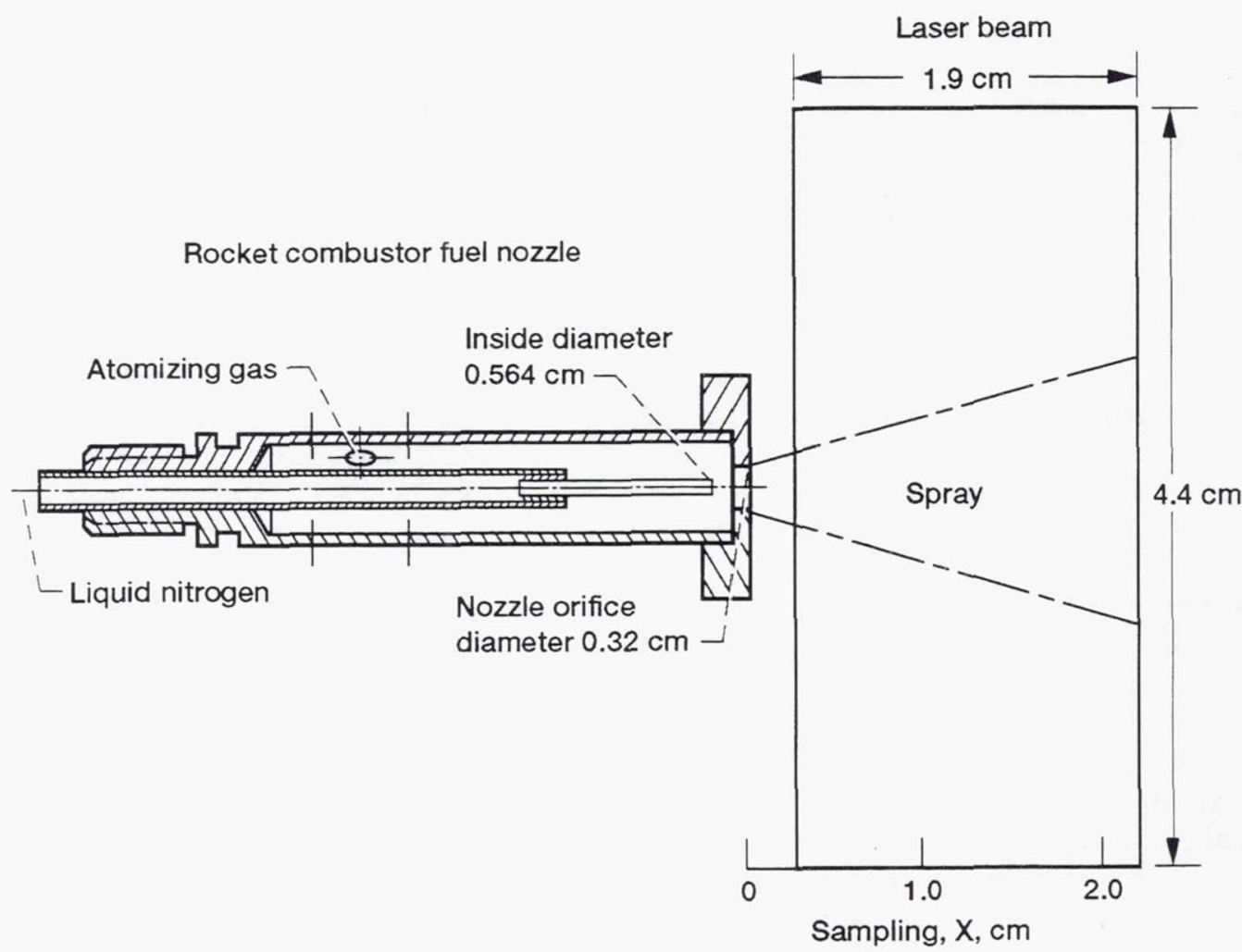

Figure 1.-Diagram of pneumatic two-fluid atomizer and sampling location of $1.9 \mathrm{~cm} \times 4.4 \mathrm{~cm}$ laser beam.

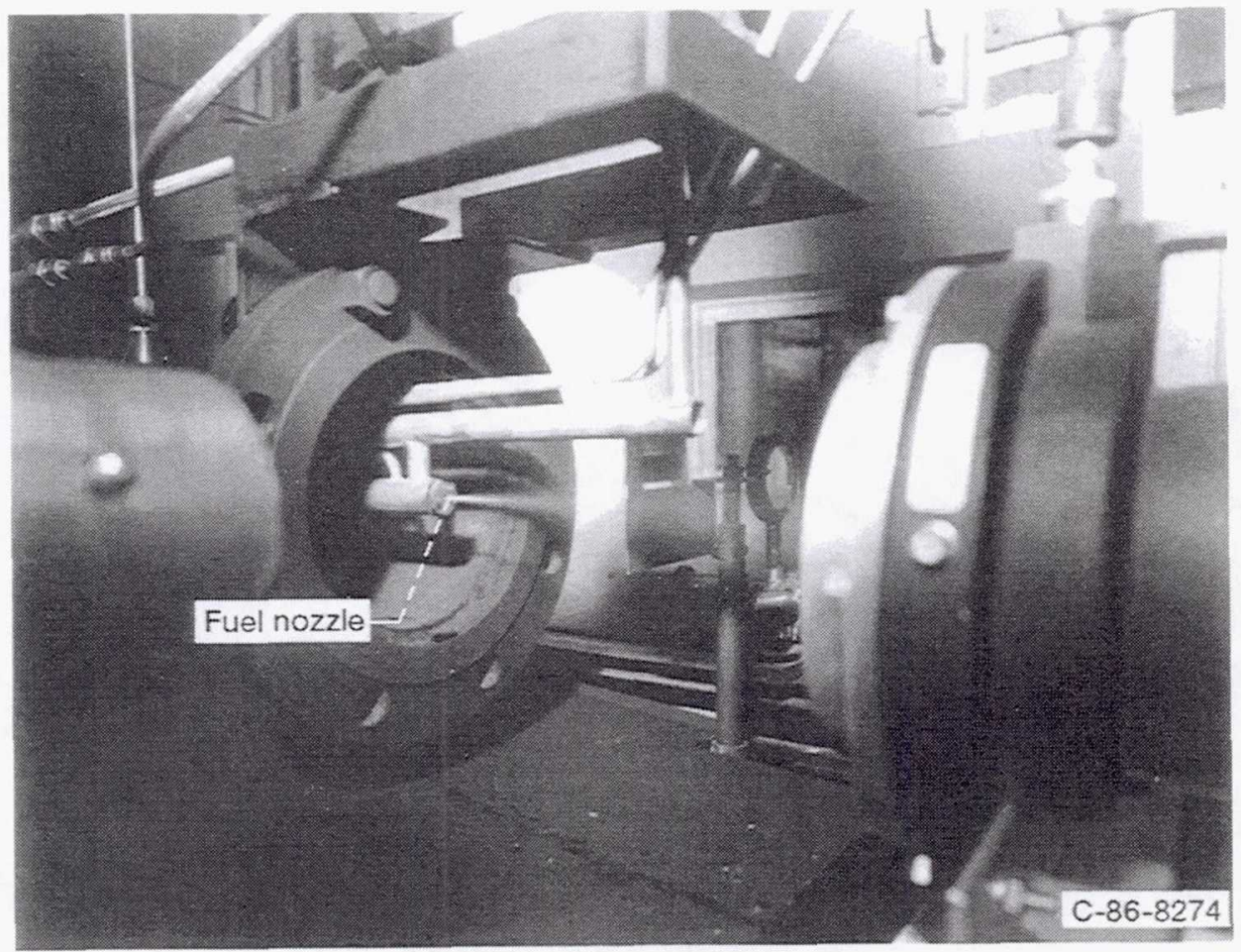

Figure 2.-Apparatus and auxiliary equipment. 


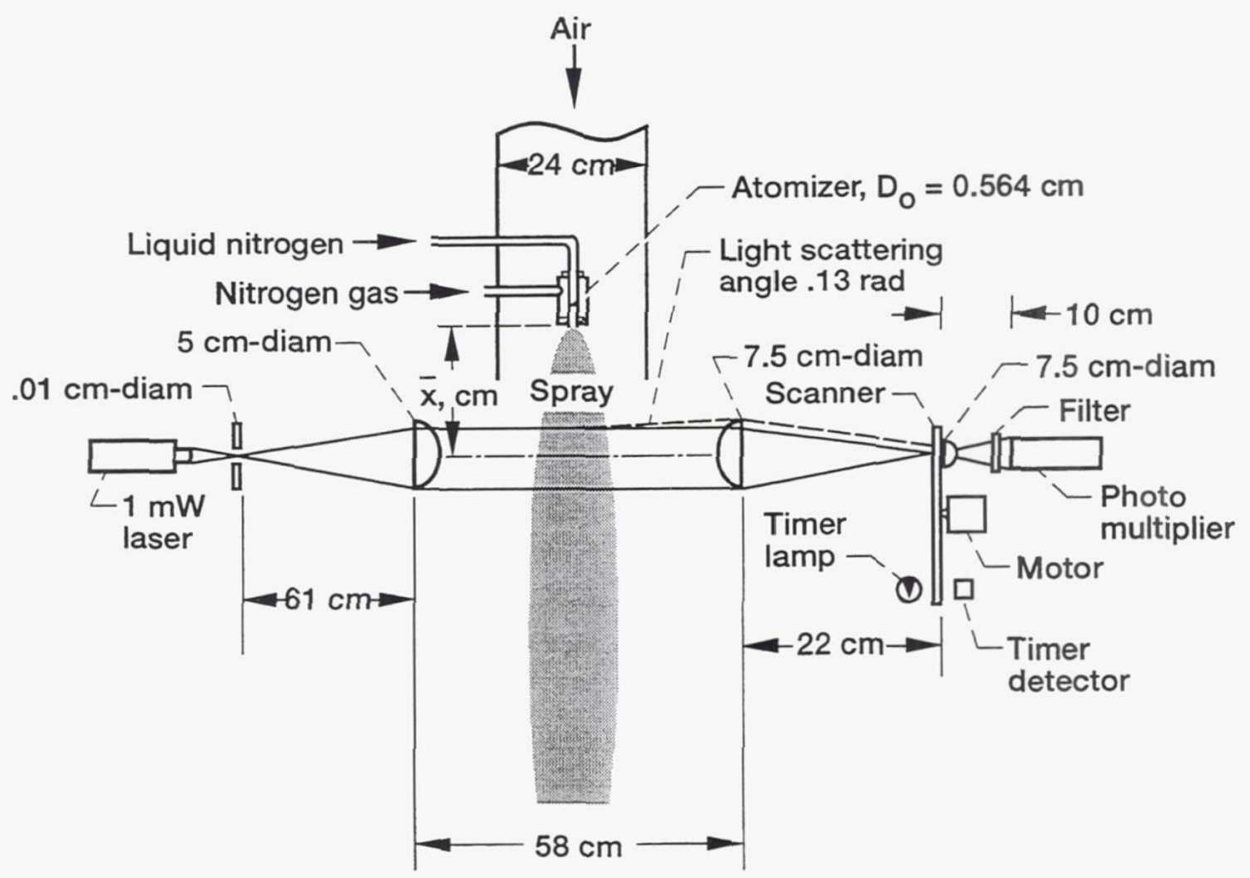

Figure 3.-Atmospheric pressure test section and optical path of scattered-light scanner. 

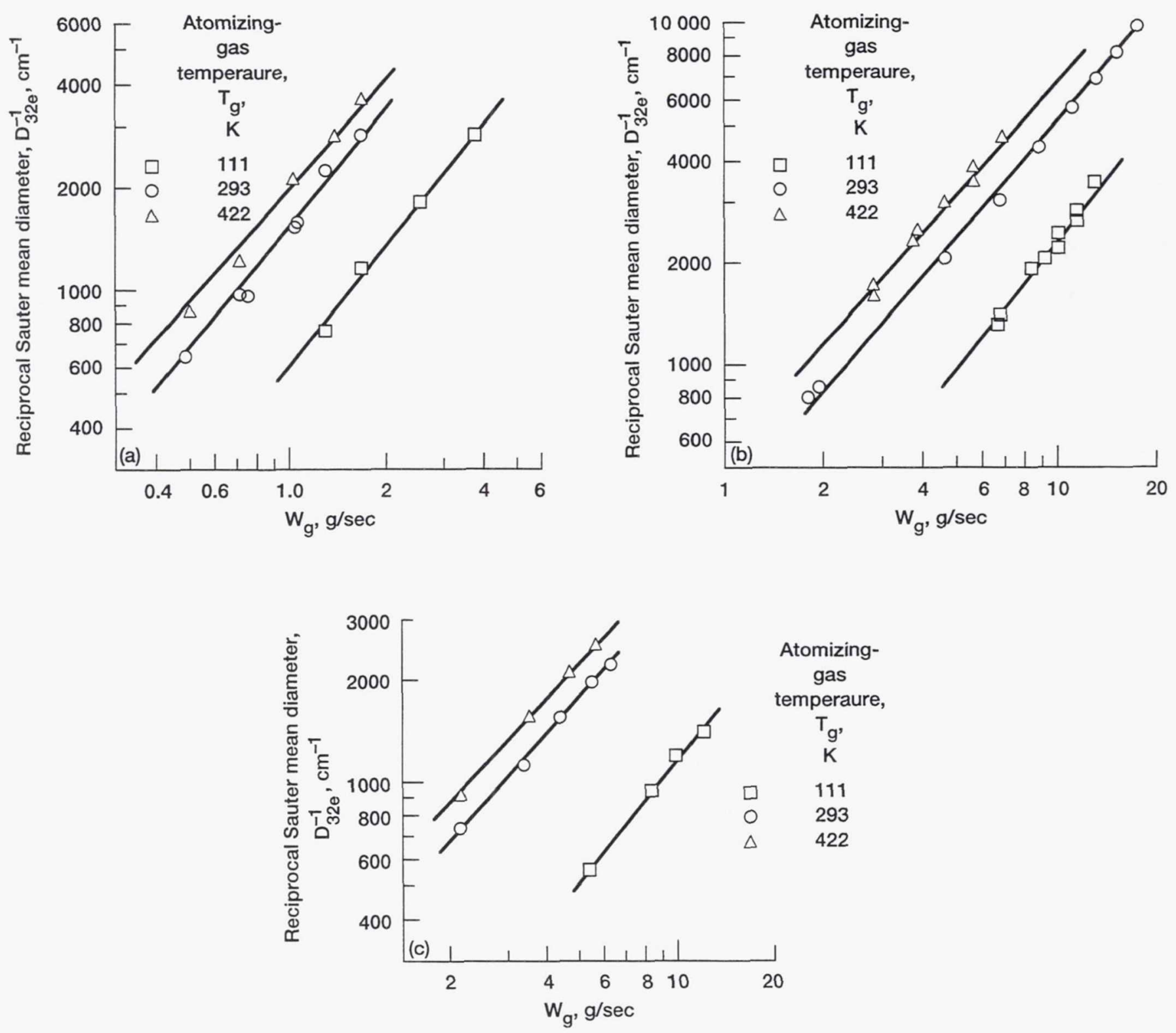

Figure 4.-Variation of reciprocal Sauter mean diameter, $\mathrm{D}_{32 \mathrm{e}}^{-1}$, with atomizing-gas flowrates of $\mathrm{He}, \mathrm{N}_{2}$ and $\mathrm{Ar}$.

(a) Helium. (b) Nitrogen. (c) Argon. 

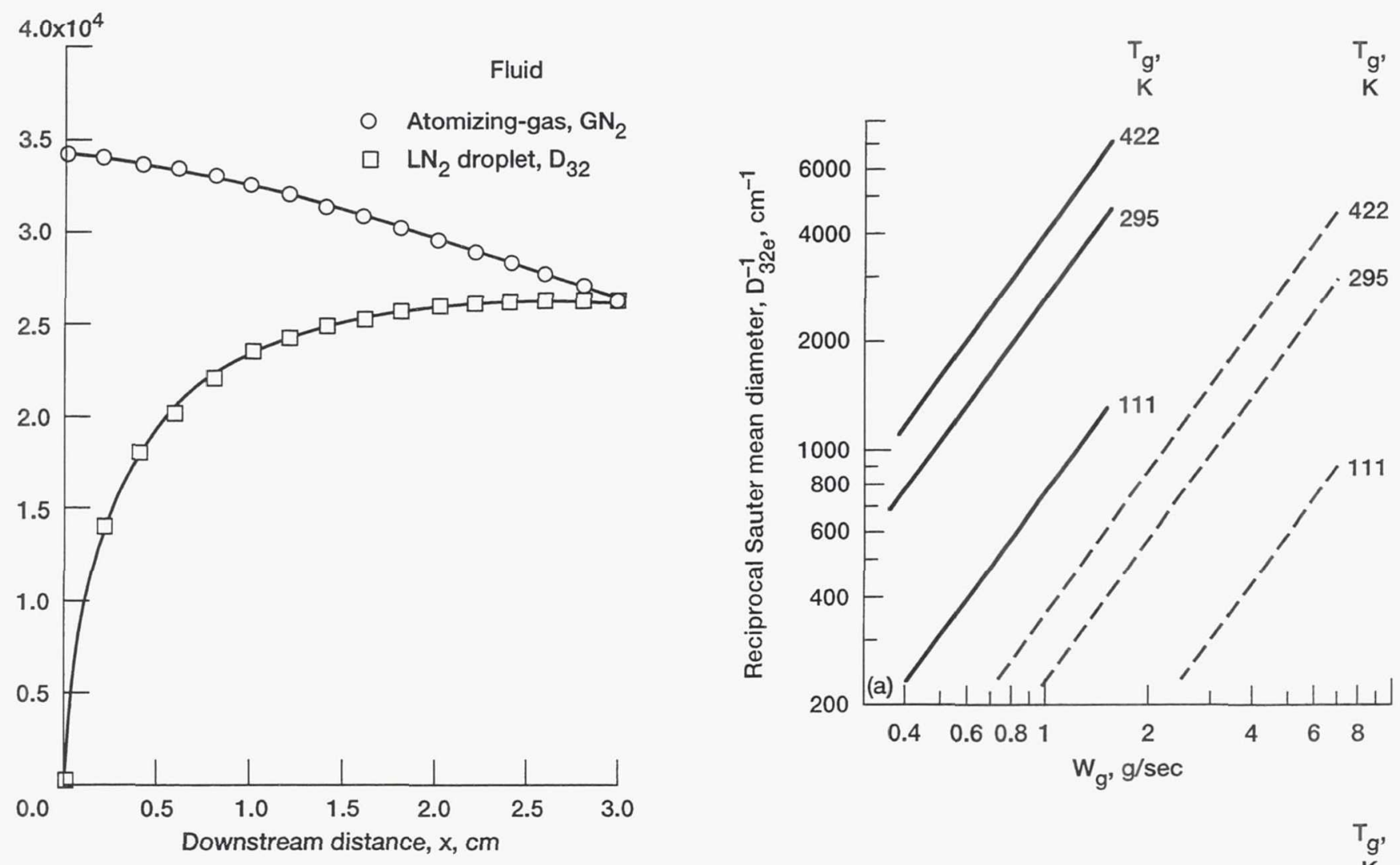

Figure 5.-Variation of fluid velocity with distance, $x$, downstream of fuel nozzle orifice. $\mathrm{T}_{\mathrm{g}}=295 \mathrm{~K}$, $\mathrm{W}_{\mathrm{g}}=4.54 \mathrm{~g} / \mathrm{sec}$.

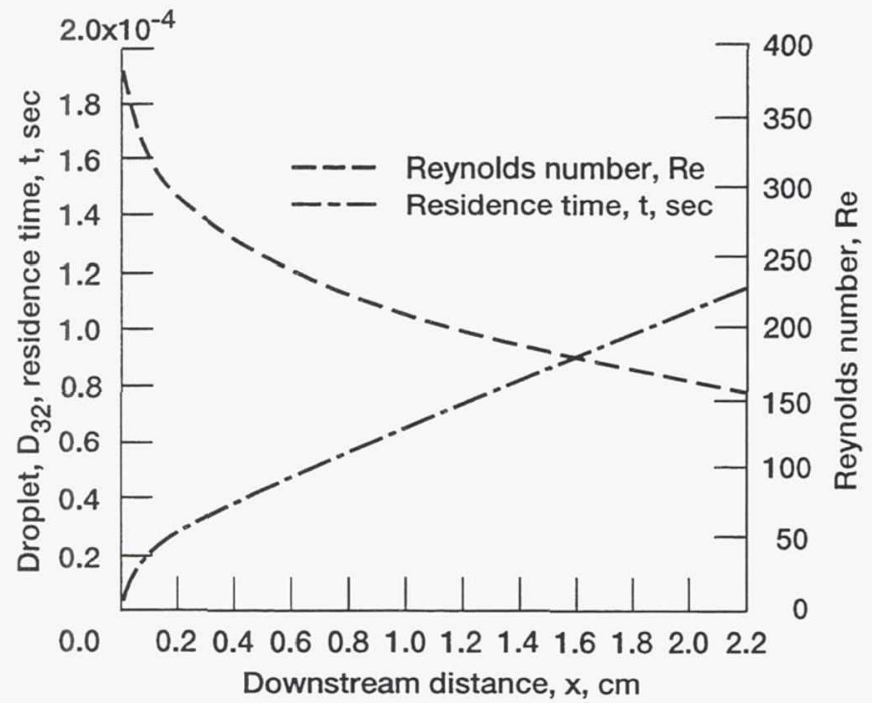

Figure 6.-Variation of residence time, $t$, and Reynolds number, Re, with distance, $x$, downstream of fuel nozzle. $T_{\mathrm{g}}=295 \mathrm{~K}, \mathrm{~W}_{\mathrm{g}}=4.54 \mathrm{~g} / \mathrm{sec}$.

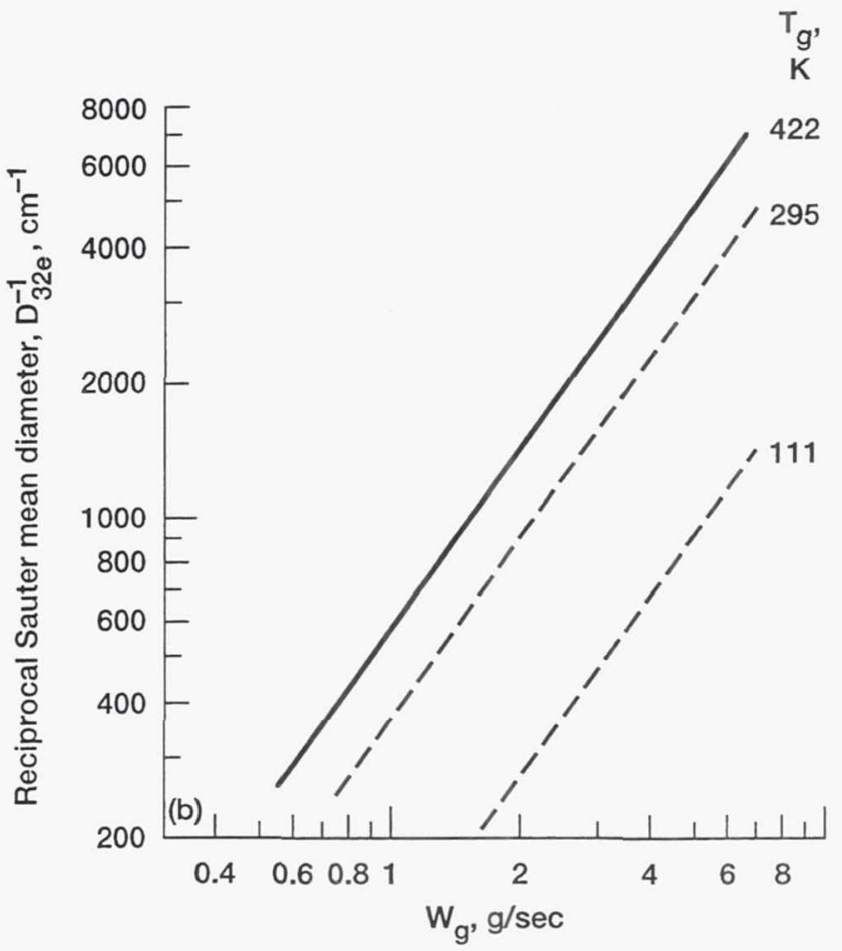

Figure 7.-Variation of reciprocal Sauter mean dimeter, $D_{32 e}^{-1}$, with atomizing-gas flowrate, $\mathrm{W}_{\mathrm{g}}$. (a) $\mathrm{He}$ and $\mathrm{GN}_{2}$. (b) Ar. 


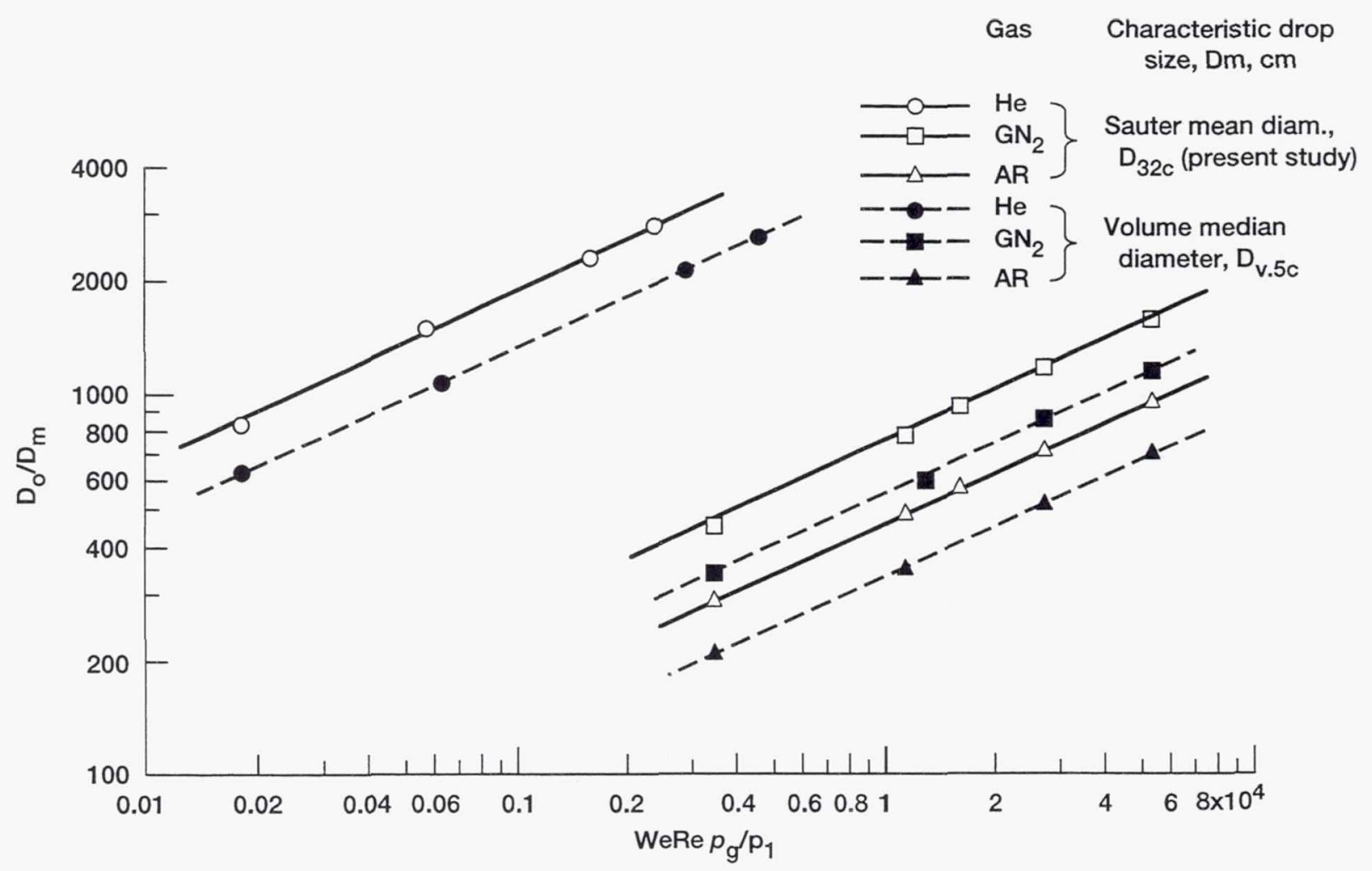

Figure 8.-Correlation of $D_{o} / D_{32 c}$ with dimensionless groups.

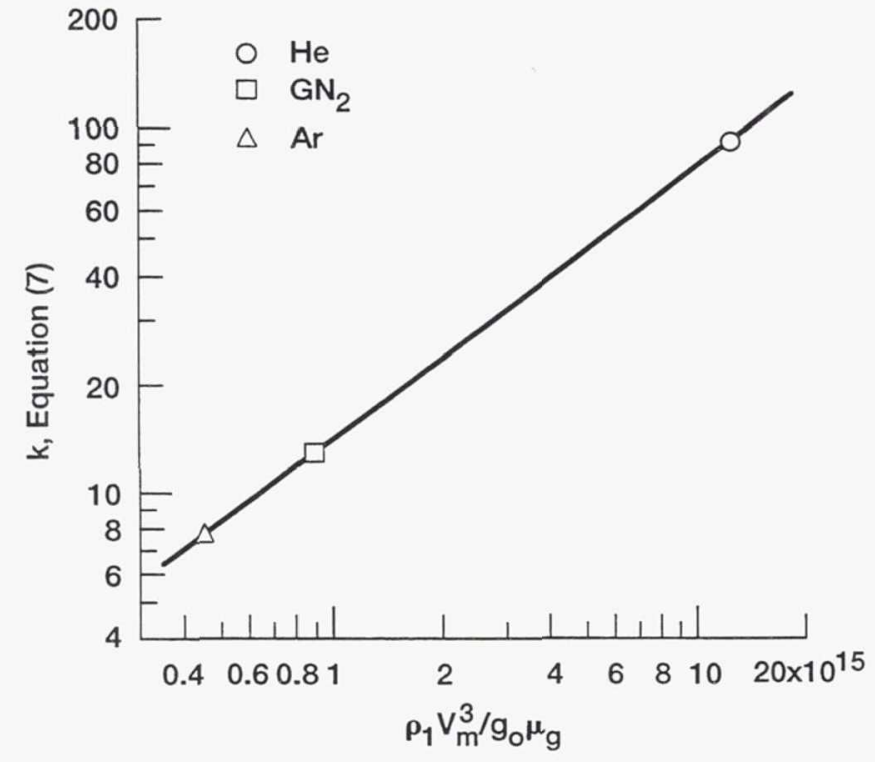

Figure 9.-Correlation of coefficient $\mathrm{k}$ with new dimensionless number for accelerating gas molecules. $\mathrm{T}_{\mathrm{g}}=295 \mathrm{~K}$.

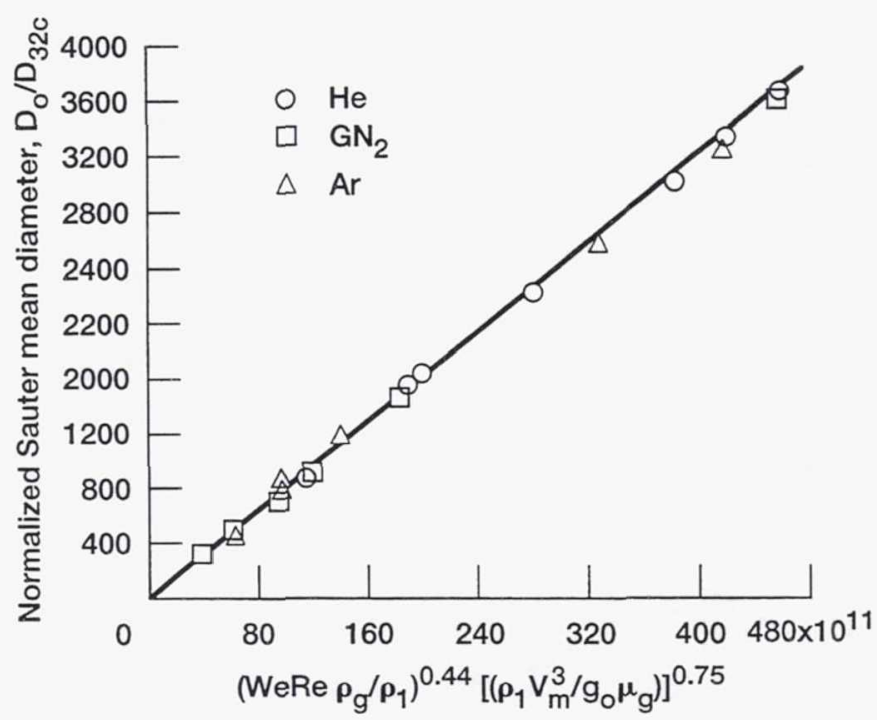

Figure 10.-Correlation of Sauter mean diameter, $\mathrm{D}_{32 \mathrm{c}}$, with dimensionless groups. 

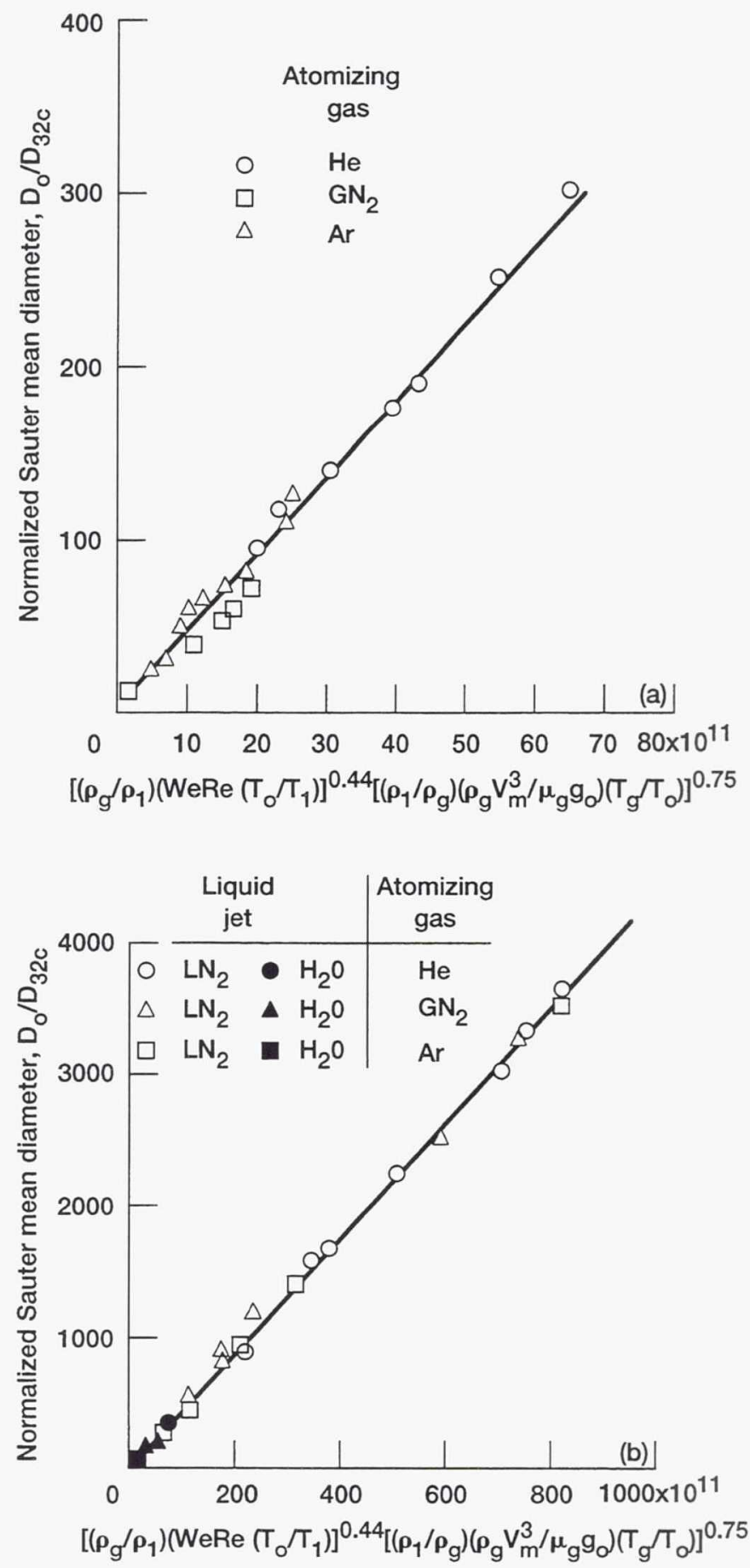

Figure 11.-Correlation of normalized $D_{32}$, with dimensionless groups, (a) for water sprays simulating fuel sprays (Ref. 3 data), (b) for water and liquid nitrogen sprays. 
Public reporting burden for this collection of information is estimated to average 1 hour per response, including the time for reviewing instructions, searching existing data sources, gathering and maintaining the data needed, and completing and reviewing the collection of information. Send comments regarding this burden estimate or any other aspect of this collection of information, including suggestions for reducing this burden, to Washington Headquarters Services, Directorate for Information Operations and Reports, 1215 Jeffers

\begin{tabular}{|l|r|}
\hline 1. AGENCY USE ONLY (Leave blank) & $\begin{array}{r}\text { 2. REPORT DATE } \\
\text { May } 1995\end{array}$ \\
\hline
\end{tabular}

\section{TITLE AND SUBTITLE}

Cryogenic and Simulated Fuel Jet Breakup in Argon, Helium and Nitrogen Gasflows

6. AUTHOR(S)

Robert D. Ingebo
3. REPORT TYPE AND DATES COVERED

Technical Memorandum

\section{FUNDING NUMBERS}

WU-505-62-52

8. PERFORMING ORGANIZATION REPORT NUMBER

E-9636

National Aeronautics and Space Administration

Lewis Research Center

Cleveland, Ohio 44135-3191

9. SPONSORING/MONITORING AGENCY NAME(S) AND ADDRESS(ES)

National Aeronautics and Space Administration

Washington, D.C. 20546-0001

10. SPONSORING/MONITORING AGENCY REPORT NUMBER

NASA TM-106923

AIAA-95-2554

\section{SUPPLEMENTARY NOTES}

Prepared for the 31st Joint Propulsion Conference cosponsored by AIAA, ASME, SAE, and ASEE, San Diego, California, July 10-12, 1995. Responsible person, Robert D. Ingebo, organization code 2650, (216) 433-3586.

12a. DISTRIBUTION/AVAILABILITY STATEMENT

12b. DISTRIBUTION CODE

Unclassified - Unlimited

Subject Category 35

This publication is available from the NASA Center for Aerospace Information, (301) 621-0390.

13. ABSTRACT (Maximum 200 words)

Two-phase flow atomization of liquid nitrogen jets was experimentally investigated. They were co-axially injected into high-velocity gas flows of helium, nitrogen and argon, respectively, and atomized internally inside a two-fluid fuel nozzle. Cryogenic sprays with relatively high specific surface areas were produced, i.e., ratios of surface area to volume were fairly high. This was indicated by values of reciprocal Sauter mean diameters, RSMD's, as measured with a scatteredlight scanning instrument developed at NASA Lewis Research Center. Correlating expressions were derived for the three atomizing gases over a gas temperature range of 111 to $422 \mathrm{~K}$. Also, the correlation was extended to include water-jet breakup data that had been previously obtained in simulating fuel jet breakup in sonic velocity gasflow. The final correlating expression included a new dimensionless molecular-scale acceleration group. It was needed to correlate RSMD data, for $\mathrm{LN}_{2}$ and $\mathrm{H}_{2} \mathrm{O}$ sprays, with the fluid properties of the liquid jets and atomizing gases used in this investigation.

\section{SUBJECT TERMS}

Fuel sprays; Two-phase flow; Liquid nitrogen; Fuel nozzles; Atomization; Droplet vaporization

\begin{tabular}{|c|c|}
\hline $\begin{array}{c}\text { 17. SECURITY CLASSIFICATION } \\
\text { OF REPORT }\end{array}$ & $\begin{array}{c}\text { 18. SECURITY CLASSIFICATION } \\
\text { Onclassified }\end{array}$ \\
$\begin{array}{c}\text { OF THIS PAGE } \\
\text { Unclassified }\end{array}$
\end{tabular}

NSN 7540-01-280-5500

19. SECURITY CLASSIFICATION
OF ABSTRACT
Unclassified
SECURITY CLASSIFICATION
Unclassified

15. NUMBER OF PAGES

15

16. PRICE CODE $\mathrm{A} 03$

20. LIMITATION OF ABSTRACT

Standard Form 298 (Rev. 2-89) Prescribed by ANSI Std. Z39-18 298-102 